\title{
Anti-tumour necrosis factor (anti-TNF) in the treatment of juvenile idiopathic arthritis-associated uveitis C Rivarola*1,2, C Hovhannessian ${ }^{1}$, A Duquesne ${ }^{1}$ and R Cimaz ${ }^{1}$
}

Address: ${ }^{1}$ Hôpital Femme Mère Enfant, Bron, France and ${ }^{2}$ Hôpital Cochin, Paris, France

* Corresponding author

from $15^{\text {th }}$ Paediatric Rheumatology European Society (PreS) Congress

London, UK. 14-17 September 2008

Published: 15 September 2008

Pediatric Rheumatology 2008, 6(SuppI I):P36 doi:I0.I I86/I546-0096-6-SI-P36

This abstract is available from: http://www.ped-rheum.com/content/6/SI/P36

(c) 2008 Rivarola et al; licensee BioMed Central Ltd.

\section{Introduction}

Chronic uveitis is associated with JIA in about $15-30 \%$ of cases. Treatment with anti-TNF agents is very effective in JIA, but their efficacy for uveitis is controversial. We present here the preliminary results of a retrospective case series of uveitis associated of JIA and treated by different anti-TNF.

\section{Objective}

To evaluate the efficacy of TNF inhibitors in JIA-associated uveitis, as well as report the cases of uveitis associated with the use of anti-TNF.

\section{Methods}

The data of 16 patients with JIA and uveitis receiving antiTNF were collected retrospectively in three French centers.

\section{Results}

Of the 16 patients, 10 were treated with etanercept $(62.5 \%), 1$ with adalimumab (6.25\%), and $5(31.2 \%)$ with infliximab. Notably, two cases of uveitis were associated with use of etanercept. In 5 patients (31.2\%) the antiTNF was changed because of lack of efficacy and/or side effects to another one (in 4/5 adalimumab). Ten patients had a complicated uveitis (cataract in 5). The number of relapses of uveitis was $4 \pm 1.35$ with the first anti-TNF, and $1.3 \pm 1.5$ with the second one. Remission of uveitis was obtained in 4 cases, 3 of them with adalimumab and one case with etanercept.

\section{Conclusion}

Anti-TNF agents have a favourable effect in JIA-associated uveitis, but adalimumab and perhaps infliximab may be more effective than etanercept, during which treatment uveitis may even develop. 